University of Warwick institutional repository: http://go.warwick.ac.uk/wrap This paper is made available online in accordance with publisher policies. Please scroll down to view the document itself. Please refer to the repository record for this item and our policy information available from the repository home page for further information.

To see the final version of this paper please visit the publisher's website. Access to the published version may require a subscription.

Author(s): Ilias Livanos, Çagri Yalkin, Imanol Nuñez

Article Title: Gender employment discrimination: Greece and the United Kingdom

Year of publication: Forthcoming

Link to published version:

http://info.emeraldinsight.com/products/journals/journals.htm?id=ijm

Publisher statement: None 


\title{
Gender employment discrimination: Greece and the United Kingdom
}

\author{
Ilias Livanos, Çagri Yalkin, Imanol Nuñez
}

a Author of correspondence. Ilias Livanos is a research associate at Warwick's Institute for Employment Research. His main interests include forecasting occupations and qualifications, labour economics and economics of higher education. Contact details: Institute for Employment Research, University of Warwick, Coventry CV4 7AL, United Kingdom

I.Livanos@warwick.ac.uk

b Cagri Yalkin is a lecturer at Kings College, University of London. Her main interests include consumer behaviour and gender. Contact details: Department of Management, King's College, Franklin-Wilkins Building, 150 Stamford St., London SE19NH.

${ }^{c}$ Imanol Nuñez is a lecturer at the Universidad Publica de Navarra, Pamplona (Spain) and a visiting researcher at Warwick's Institute for Employment Research. His main research interests include labour market regulation and economics of contracts. Contact details: Departamento de Gestión de Empresas, Universidad Pública de Navarra, Campus de Arrosadia, 31006 Pamplona, Spain, imanol.nunez@unavarra.es 


\begin{abstract}
Purpose: This study examines the factors affecting the labour market status of females in Greece and the UK respectively, and also attempts to explore what accounts for the differences in the employment status between males and females. In particular, the study assesses whether these differences can be explained by employees' endowments or by discrimination in the labour market.
\end{abstract}

Methodology-Approach: Labour Force Survey (LFS) data are used to examine the impact of observable characteristics on female labour market participation, unemployment and self-employment through the use of logit models. An extension of the Oaxaca-Blinder decomposition technique is used to estimate the gender employment discrimination gap.

Findings: Clear evidence of gender differences was found in both countries, although differences are substantially larger in the case of Greece. Evidence of female employment discrimination was also found in both labour markets.

Originality/Value: The paper explores the factors affecting the labour market situation of females, and for the first time, assesses the level of gender employment discrimination in Greece and the UK analysing the differences on the unemployment rates of males and females.

Keywords: Employment, discrimination, gender, United Kingdom, Greece.

Classification: Research paper

Acknowledgments: The authors are grateful to Professor Derek Bosworth for his valuable comments and suggestions. Imanol Nuñez gratefully acknowledges the financial support of the Spanish Ministry of Education and Science under the Project SEC2007-67737-C03-02/ECON. 


\section{Introduction}

During the last century, the size of female labour force has rapidly grown in most developed countries. However, the employment conditions of females have not always matched those of males. Often, female workers have difficulties in accessing higher level employment positions; it is harder for them to get promoted, and as research has demonstrated, they are systematically underpaid. Discrimination theorists argue that female employment conditions are negatively affected by certain stereotypes with regard to their commitment to their professional career (Anker, 1997). As a consequence, employing males is seen as a more secure choice than employing females whereas males in general receive better treatment in the labour market.

The literature in this area has mainly focused on the analysis of gender wage discrimination. A large number of studies of the Greek labour market (e.g. Leibenstein, 1967; Kanellopoulos, 1980, 1993; Psacharopoulos, 1983) have indicated that a considerable portion of the wage gap between males and females is due to discrimination in the labour market. This gap is found to be one of the largest in Europe (Kottis, 1984, Cholezas, 2005) and there is no evidence that the gap is decreasing (Cholezas and Tsakloglu, 2005). In fact, Kanellopoulos and Mavromaras (2002) argue that the wage gap increased between 1988 and 1999, and they suggest that discrimination against females is the most important identifiable reason for the increasing wage differentials between the two genders.

Numerous comparative studies show that wage gap discrimination is far from being homogenous across countries (Blau and Kahn, 2003). Cross-country variations are 
observable not only in wages but also in some pivotal features of females' labour market, such as rates of participation and employment (Azmat et al, 2006). Olivetti and Petrongolo (2006) argue that the variations on the participation patterns across countries may be related to wage differentials. The same authors suggest that in countries where female unemployment is high, the human capital attainments of female employees may need to be higher than that of males. In that case, females will, in general, be more educated than their male colleagues, and this would lead to a reduction on the wage gap. According to Olivetti and Petrongolo (2006), the above could explain the negative relationship between the wage gap and the employment gap. In other words, discrimination against females may not be exclusive to wages but could also be affecting their likelihood of being employed. This will be the case if the human capital required to enter the labour market is unjustifiably higher for females than for males.

A number of earlier studies have analysed gender employment discrimination (e.g. Long, 1976, Finn, 1983, Jones and Walsh, 1991), but they have generally focused on either very particular industries or groups of workers. The present paper extends the analysis of employment discrimination to the whole female labour force of two very different labour markets: Greece, which is a highly regulated labour market with low levels of female participation and the UK, which is a deregulated labour market with high levels of participation. A recent OECD (2003) report and some other empirical studies (Azmat et al, 2002. Olivetti and Petrongolo, 2006) have found notable differences between Southern European and Anglo-Saxon economies in employment indicators, such as gender wage and employment gaps. Southern European economies are characterised by large differences in unemployment and smaller wage 
differentials. Anglo-Saxon economies show the opposite evidence, namely small or negative unemployment gaps and large wage differentials. These differences suggest that Southern European and Anglo-Saxon labour market institutions are operating quite differently. Thus, the examination of gender employment discrimination in the context of two such diverse economies provides a promising area of study.

This investigation is also motivated by the fact that most of OECD countries are in a process of redefining their policies to eradicate gender discrimination from the labour markets (Jaumotte, 2003). These policies include changes in family taxation, childcare subsidies and child benefits, parental leaves, flexible working patterns and anti-discrimination laws. The main objective of these policies is to ensure that females have equal opportunities to participate in the labour market. This study aims at guiding the implementation phase of these policies by providing novel evidence on the magnitude and factors of employment discrimination against females. The empirical objectives of this paper are two: the first is to identify the factors affecting the labour market status (participation, unemployment, and self-employment) of females in the Greek and the UK labour markets, and the second is to estimate the level of the gender employment discrimination using the likelihood of unemployment as measure.

The analysis is conducted using Greek and UK LFS data in order to observe how the impact of the attributes of an individual varies between the two countries. In addition, an extension of the Oaxaca-Blinder technique is used to decompose the differences in the employment positions of males and females into two portions, one of which is due 
to the endowments of the individuals (explained part) and one which is due to differences in the coefficients (unexplained part).

The paper is organised as follows: the next section describes the principal characteristics of the female labour markets of Greece and the UK. Section 3 presents the data and the methodology used. Section 4 compares the results for the probability of participation, unemployment and self employment of females, and Section 5 assesses the issue of gender employment discrimination. Finally, Section 6 discusses the main findings of the paper.

\section{The female labour market in Greece and United Kingdom}

A descriptive analysis.

Over the last few decades, female labour market participation has increased significantly in most OECD countries (OECD, 2003). In Greece, this trend has been amongst the strongest observed. However, female participation in Greece is still low, and is actually amongst the lowest within the European Union (see Figure 1). On the other hand, female participation in the UK is significantly higher and, indeed, is above the EU average.

\section{[Figure 1 here]}

In addition to the low participation rates, females in Greece face high rates of unemployment. Indeed, as the OECD (2005) notes, the high rates of female unemployment are one of main characteristics of the Greek labour market. Figure 2 depicts the unemployment rates over the period 1993-2004. As shown, Greek female 
unemployment is higher than the average EU level, with a clear cyclical pattern generated by the economic up- and down-turns. In contrast, females in the UK face low levels of unemployment, lower than the EU average, and a much smaller cyclical component.

\section{[Figure 2 here]}

Another key characteristic of the Greek labour market is the high number of selfemployed females. Figure 3 depicts the trends of self-employment for Greece ${ }^{1}$, the UK and the EU average. Rates of female self-employment in the Greek labour market are high, reflecting the structure of the Greek economy, where production activities generally take place within small family businesses which females either run or are employed within. With regards the UK labour market, female self-employment is considerably lower.

\section{[Figure 3 here]}

The occupational composition of the Greek economy, where agriculture, retailing, commerce and tourism are strongly represented, increases the share of selfemployment, especially in the case of female workers who have been traditionally involved in these sectors. On the contrary, the UK economy has a greater proportion of consolidated firms that bargain with their employees about conditions of work, drawing explicit contracts of employment.

\footnotetext{
${ }^{1}$ Figure 3 shows a break in the data for female self-employment in Greece for 2000. This break is more likely to result from changes in the methodology of the Greek LFS rather than reveal real changes in the patters of self-employment in Greece for that particular year.
} 
Table 1 illustrates the composition of female labour market participation, unemployment, and self-employment broken down by various individual characteristics included in our analysis. Looking at Table 1 we can observe some interesting features of the two countries. For instance, the total sample in Greece has a higher share $(60.3 \%)$ of married females than the UK (43.4\%), which highlights the strong family bonds in the Greek society. Further, married females in Greece have a very high share of total labour market participation (66.8\%), which is an indication of the high financial responsibilities that married females face.

Greece has a distinctively older female population than the UK. For example, for the full sample, the share of UK females aged $15-24$ is $17.5 \%$ compared to only $8.2 \%$ for Greece. This pinpoints the wide problem of ageing of the population that Greece faces. Regarding participation in the labour market, it is seen that young females (under 24) in Greece have a very low rate: $4.3 \%$ against $14.2 \%$ in the UK. This, on the one hand reflects the financial support that Greek young females receive from home, and on the other hand the large trend towards higher education in both countries.

Regarding qualifications structure it is not easy to make direct comparisons between the two countries since the classifications used are not comparable. Nevertheless, for the total sample, Greece has a distinctive higher share of females with primary level of qualification or below (55\%) compared to $38.1 \%$ for the UK. This has to do with the age structure of the Greek population and with the fact that females in Greece have only recently began to enter the labour market and thus to acquire higher qualifications. However, this is also an outcome of the lack of flexible working 
patterns that young females could use, mainly while studying, in order to participate in the labour market and gain some experience.

Finally, Greece has a smaller share of females (17.4\% against $22 \%$ on the full sample) that report themselves as head of households $(\mathrm{HH})$, which is mainly a societal issue since females have traditionally been protected family members, either as spouses or as children. Regarding the latter (children), this is also supported by the fact that the share of females reporting themselves as children in the household is significantly higher in Greece (26\%) than in the UK (11.9\%). However, this is also an outcome of the poor benefit system in Greece that withholds young females from gaining early independence from home.

\section{[Table 1 here]}

\section{Economic and institutional factors.}

The picture painted above is the result of profound differences in labour market structures which arise from both economic and institutional factors.

Regarding the UK, female participation has been considerably high since World War II. This has greatly been due to the structure of the UK economy, and in particular due to the dominant role of the tertiary sector. In Greece, the increase of female participation has occurred much more recently. In particular, while the contraction of the primary sector during the 1960's reduced female participation and increased their rates of unemployment, the expansion of the tertiary sector in the 1990s has offered females many employment opportunities and has increased their employment levels. 
Regarding institutional factors and their impact on the Greek female labour market, changes in the Greek Constitution in 2001 had important implications for female employment. In particular, the new Constitution encourages governmental actions aiming at the "The adoption of positive measures for the promotion of equality between men and women" (Article 116, Greek Constitution).

The main institutional factors can be summarized as follows:

Anti discrimination Laws. The first anti-discrimination legislation in Greece was introduced by the Article 22 of the 1975 Constitution, which established that "All workers have the right to equal pay for work of equal value". In 1997, antidiscrimination was reinforced by the adoption of the Amsterdam treaty that inspired most of the institutional changes recently adopted in Greece, such as the reform of the 2001 Constitution. In the UK, measures against discrimination were adopted much earlier than most European countries. For example, the Equal Pay Act and the Sex Discrimination Act were enacted in the early 70s. However, the results of legal interventions are not immediately evident, especially in the case of policies oriented to increase female participation (Jaumotte, 2003), and thus it is not straightforward to assess their effectiveness.

Availability of childcare facilities. In the last years, the availability of childcare facilities in Greece has increased significantly. In particular, in 1997 the nurseries and primary schools extended their opening hours up to 4 p.m. However, as Nicolitsas (2006) points out, the institutional measures in Greece are lagging behind the European standards in creating favourable conditions for the employment of females 
with children while public support for childcare is very low. To illustrate, in 2006 public spending for childcare services accounted for only $0.4 \%$ of the GDP compared to $0.7 \%$ for all OECD countries (OECD, 2007). In the case of the UK, the supply of public childcare facilities is greater than in Greece and it is complemented by the offer of private childcare options. Thus, female participation is facilitated to a great extent.

Flexible forms of work. The availability of some flexible forms of work, such as parttime, seasonal work, and work from home facilitates a balance between work and family, and thus increases female participation. However, this type of work is not very common in Greece. This, according to Nicolitsas (2006), may be due to the high level of non-wage costs and administrative burdens. Regarding the UK, the strong dynamism of the demand and the flexibility of the labour market creates a large supply of part-time positions that help to accommodate the needs of many female workers (Del Boca et al, 2005).

\section{Data and Methods}

The analysis draws on micro data from Labour Force Surveys (LFS) of Greece and of the UK for the second (spring) quarter. The period examined is 2000-2004 for Greece and 2001-2004 for the UK. The Greek LFS is conducted by the National Statistical Service of Greece (ESYE) and collects information from 30,000 households and 80,000 individuals approximately. The UK LFS, conducted by the Office for National Statistics, and contains information for approximately 80,000 households and 120,000 individuals. Both the questions and the definitions used are internationally agreed on and are based on the European LFS (European Communities, 2003). 
The analysis conducted combines two different methodologies. The estimation of the factors affecting the probabilities of participation, self-employment and unemployment is performed using traditional logit models. The estimation of female discrimination with regard to the probability of unemployment uses an extension of the Oaxaca (1973) - Blinder (1973) decomposition technique. The adaptation of the Oaxaca-Blinder (OB) methodology for categorical dependent variables is developed by Gomulka and Stern (1990) for a probit model and by Nielsen (1998) for a logit model. Recently, Fairlie (2003) systematised the technical features of these models for a wider range of applications. Since the logit model is a well-known econometric specification $^{2}$, the present discussion focuses mainly on the description of the extension of the $\mathrm{OB}$ methodology for categorical dependent variables.

The OB technique decomposes inter-group differences in mean levels of outcomes into those due to different endowments (observable characteristics) and those due to different effects of coefficients (unobservable characteristics or discrimination). In this case, the categorical dependent variable estimated by the logit model is the unemployment status, where $y=1$ if an individual is unemployed and $y=0$ if employed. Maximizing the logit log-likelihood function for the sample of males and females provides the estimated parameters for the probability of being unemployed in the form:

$$
\begin{aligned}
& l(\beta, \delta)=\sum_{i=1}^{N m}\left\{y_{m} \ln F\left[x_{m} \beta\right]+\left(1-y_{m}\right) \ln \left(1-F\left[x_{m} \beta\right]\right\}+\right. \\
& \sum_{i=1}^{N f}\left\{y_{f} \ln F\left[x_{m} \delta\right]+\left(1-y_{f}\right) \ln \left(1-F\left[x_{f} \delta\right]\right\}\right.
\end{aligned}
$$

\footnotetext{
${ }^{2}$ A short and comprehensive description of the logit model variety used in this paper can be found in Livanos (2007).
} 
so,

$$
\begin{aligned}
& \overline{p_{m}}=\sum_{i=1}^{N m} F\left[x_{m} \beta\right] / m \\
& \overline{p_{f}}=\sum_{i=1}^{N f} F\left[x_{f} \delta\right] / f
\end{aligned}
$$

where $\overline{p_{m}}$ and $\overline{p_{f}}$ are the average probabilities of unemployment for males and females respectively, $\mathrm{Nm}$ and $N f$ are the number of observations for males $(\mathrm{m})$ and females $(f), x$ the set of explanatory variables and $\beta$ and $\delta$ the estimated parameters of the regression for males and females respectively. Following the OB methodology, the average probability of females being unemployed if they were treated as males is calculated as:

$\overline{p_{f m}}=\sum_{i=1}^{N f} F\left[x_{f} \beta\right] / f$

where the values of $\overline{p_{f m}}$ are obtained by combining the explanatory variables for females with the estimated parameters from the male regression, $\beta$. The male/female gap (in this case female/male gap, as the probability of being unemployed for females is normally higher $),\left(\overline{p_{f}}-\overline{p_{m}}\right)$ can be decomposed in two parts; the discrimination gap $D=\left(\overline{p_{f}}-\overline{p_{f m}}\right)$ and the gap explained by the endowments, $E=\left(\overline{p_{f m}}-\overline{p_{m}}\right)$. In this specification, the interaction between the explained and the unexplained components is allocated to the explained. As we will further discuss when 
commenting the results, this definition of the interaction term is to ensure that the measurement of the discriminatory gap is not overestimated.

The econometric specification of the estimated logit equation is expressed as follows:

$\operatorname{Ln}\left[P_{i} /\left(1-P_{i}\right)\right]=\alpha+X_{i 1} \beta_{1}+X_{i 2} \beta_{2}+X_{i 3} \beta_{3}+X_{i 4} \beta_{4}+X_{i 5} \beta_{5}+X_{i 6} \beta_{6}+X_{i 7} \beta_{7}+X_{i 8} \beta_{8+}$

$\varepsilon_{i}$

Where $\mathrm{X}_{\mathrm{i} 1}$ denotes marital status, $\mathrm{X}_{\mathrm{i} 2}$ denotes sector of economic activity, $\mathrm{X}_{\mathrm{i} 3}$ denotes age group, $\mathrm{X}_{\mathrm{i} 4}$ denotes region of residence, $\mathrm{X}_{\mathrm{i} 5}$ denotes level of qualification, $\mathrm{X}_{\mathrm{i} 6}$ denotes occupational category, $X_{\mathrm{i} 7}$ denotes the relationship with the head of household and $\mathrm{X}_{\mathrm{i} 8}$ denotes a time trend. The economic activity and occupational category are only available for the case of the self employed. Thus, the logit equations for participation and unemployment do not include variables $\mathrm{X}_{\mathrm{i} 2}$ and $\mathrm{X}_{\mathrm{i} 6}$ among the explanatory variables.

\section{Determinants of the employment outcome for female workers}

The results of the econometric analysis for Greece and the UK are reported in Tables 2 and 3 respectively. The coefficients are computed using maximum likelihood estimation (MLE). The results are reasonably robust. The chi-square test suggests that both models are statistically significant (chi2 $=0.000$ ), and most of the coefficients are significant at the $1 \%$ level. Tables 2 and 3 present the odds ratio of the estimated models. The odds ratio is the probability of an event happening divided by the probability of not happening (i.e. the alternative event occurs). For example, for the incidence of participation (column 1) the odds ratio of 0.69 for divorced females in 
Greece (Table 2) suggests that a divorced female has 0.69 times the probability of a married female of participating in the labour market. In general, an odds ratio greater than unity means that the odds of the positive outcome occurring for a category are greater than that for the category set as the reference category.

Factors affecting female employment status in Greece.

The results of the analysis on the factors affecting female employment status for Greece are presented in Table 2.

\section{[Table 2 here]}

The female participation results indicate that marital status is a factor affecting considerably the chances of participating in the labour market. In particular, it is found that married females have higher probabilities of participation than singles, divorced or widow females. This can be attributed to the increasing financial needs and responsibilities of the married females. On the other hand, singles have lower probabilities of participation as due to the structure of the Greek society, they are supported by their families, and, thus, have fewer incentives to be economically active.

Further, when females are head of their household $(\mathrm{HH})$, they have higher chances of participating the labor market. Similar to marital status, a $\mathrm{HH}$ has more responsibilities, and, therefore, is driven to participate in the world of work. The level of education also affects participation. In particular, university graduates in Greece have a higher probability of being economically active than those with primary 
education only and than those with basic qualifications. Nevertheless, university graduates have lower chances of participation than post-graduate degree holders, holders of technical university qualifications and holders of vocational qualifications. This finding serves to suggest that education is seen as a mean of entering the labour market, since the higher is the education level the higher are the chances of participating in the labour market.

Turning to unemployment, the chances of its incidence are found to be affected by various factors. Starting with marital status, married females have lower chances of unemployment than all other groups. For instance, single females have 3.5 times greater chances of being unemployed than married ones. In addition, $\mathrm{HH}$ also have lower odds of being unemployed. To illustrate, a female who is a spouse or partner in the household has 23 times greater odds of unemployment than a female who is HH. These large differences reflect the fact that married females or HH's have greater financial responsibilities than non-married or non- $\mathrm{HH}$ females. With regards to $\mathrm{HH}$ in Greece, it is important to note that the financial aid from the Greek government for single mothers, etc. is considerably low. Thus, female heads of households have a much greater incentive to enter employment.

Regarding the impact of educational level on unemployment, university graduates have a higher probability of being unemployed than post graduates and females that hold other types of higher education. On the other hand, females with no higher education have higher chances of unemployment than graduates. This finding highlights the importance of higher education as a way of finding a job. Nevertheless, the fact that graduates face higher chances of unemployment than females that have 
other types of further education reveals a wider problem of the Greek labour market, which is characterised by high levels of graduate unemployment. For instance, the studies of Livanos $(2007$; 2008) found evidence that the level of education neither affects the probability of being employed or unemployed, nor the probability of being short or long-term unemployed.

Another important factor that affects the incidence of female unemployment is the region of residence. In particular, the evidence suggests that females residing in Athens have a much lower probability of being unemployed than females residing in the rest of Greece. This reflects the trends in the Greek economy, such as the increasing share of the service sector in total employment, whose activities are to some degree concentrated in Athens, as well as the decline in agriculture and manufacturing, which are the main activities of regions outside Athens. On the other hand, this finding is also an outcome of the low levels of geographical mobility which do not facilitate commuting for working purposes.

Regarding self-employment, marital status was again found to affect the chances of females being self-employed. In particular, married females have a lower probability of being self-employed than the two other groups, but higher than divorced. This is because married females have responsibilities at home and may prefer to be employed by someone else, and bring a steady income into the household rather than run their own business that requires more time and effort. The region of residence is another factor affecting the incidence of self-employment in Greece. The female residents of Athens have lower probabilities of being entrepreneurs than females that reside in other regions. Also, most private sector multi-national firms and large domestic 
employers are based in Athens and, therefore, individuals in Athens are more likely to be employed by such firms than those in other regions. In general, self-employment is concentrated outside Athens and is often expressed in the form of small family businesses that operate in industries such as manufacturing, agriculture, fishery and tourism. Indicative of this is the fact that in regions such as the North Aegean and Ionian Islands, the probability of being self-employed is much greater (odds ratios of 2.15 and 1.93 respectively) than in Athens.

Finally, female self-employment in Greece is mainly expressed in the context of unskilled occupations, in which females with low levels of qualifications usually operate. In particular, 58\% (Table 1) of the total self-employment in Greece corresponds to females with low levels of education (primary or below), which is also reflected on the higher odds ratio (1.4, see Table 2$)$ of self-employed females with such education level. This result could suggest that female self-employment in Greece could be a form of precarious employment aiming to increase flexibility and reduce dismissal costs. 
Comparative analysis of factors affecting female employment status in Greece and the $U K$.

Table 3 illustrates the results for the UK.

\section{[Table 3 here]}

In the case of female participation, the results vary substantially between the two countries. Regarding marital status, the chances of participating in the UK labour market are higher for both single (1.59) and divorced (1.51) females than for married ones. In the UK, the female participation, and married ones in particular, is mainly determined by the number of children (Gomulka and Stern, 1990), which is generally lower for single and divorced females. This finding is opposite to the one obtained for Greece where married females are more likely to participate in the labour force. However, similar to the case of Greece, the probability of participation is significantly lower for widows than for married women. Regarding the $\mathrm{HH}$, the findings for the UK are again opposite of those for Greece. In particular, females who are HH in the UK have lower odds of labour market participation than non-HHs. This divergence may reflect the differences in the benefit systems of the UK and Greece, as the UK welfare system is quite generous and supports females (especially single parents) and, as a consequence, females who receive benefits have less incentive to participate in the labour market. On the contrary, in Greece, the benefit system is less generous and, therefore, females with family responsibilities are driven to participate in the labour market in order to meet their financial needs. On the other hand, females in Greece 
that do not participate in the labour market may as well decide to stay with their families rather than become $\mathrm{HH}$.

The positive relationship between education and participation is stronger in the UK, and the coefficients are consistently higher across subsequent levels of education. This result is in line with findings of other studies (Gutierrez-Domenech and Bell, 2004). The time trend suggests that female's participation in the Greek labour market is increasing over time, and this tendency is stronger than in the case of the UK. Finally, both the region of residence and the age of females are found to affect the probabilities of participation in both countries. There are clearly important regional variations, with the highest odds ratio (which means lower chances of participation) in Northern Greece and in the East Midlands in the UK. Regarding Greece, participation is lower in regions that unemployment is generally high. This might serve to suggest that females residing in these areas are actually discouraged by not being able to find a job, and thus decide not to participate in the labour market. In terms of age, in the UK there is a clear U-shaped relationship around the main child bearing age, although participation falls amongst the oldest group. In the case of Greece, the youngest group has low participation, which is an outcome of them continuing into education as well as other cultural and societal factors similar to those outlined above.

Regarding differences in factors affecting the likelihood of unemployment, we find that single and divorced females in the UK have lower odds of being unemployed than their married counterparts. In terms of the relation to the $\mathrm{HH}$, once again, the situation in the UK is the opposite of that in Greece. In the UK, a female spouse or partner has a lower probability of being unemployed than a female who is head of the 
household. As in the case of labour market participation, this difference between the two counties can be attributed, in part, to differences in their welfare systems. In terms of the effect of education, as expected, the incidence of unemployment varies considerably across most levels of education in the UK, as it is higher among nonqualified females. This variation appears to be more consistent in the UK than in Greece. Regarding the effect of the region of residence, the situation is again is found to be the opposite in the two countries. In particular, while female residents of Athens are found to have lower chances of unemployment than females residing outside Athens, in the UK the situation is opposite. In particular, females residing in London have a higher probability of being unemployed than females residing outside the UK capital, with the exceptions of Wales and Northern Ireland. Nevertheless, the comparison cannot be direct since in the UK commuting for working purposes is very popular and thus the region of residence and region of work may not be the same. On the other hand, in Greece most of the economic activities of the growing tertiary sector are concentrated in Athens, while most of the rest, such as rural economies, are based on either agriculture and manufacturing or tourism. Regions that are based on agriculture or manufacturing (mainly Northern regions) face the biggest problems since employment in these sectors is contracting. On the other hand, those that are based on tourism (mainly Southern regions) are generally better off than the rest of the regions. Thus, the nature of the local economies seems to determine the chances of unemployment for its residents.

Age is also a factor affecting female unemployment in both countries. In the case of Greece, young females (15-24) have an odds ratio 5.3 times greater than the reference group (25-34). This reflects a wider problem, which is not specific to the Greek labour 
market, as young individuals in general face difficulty finding employment mainly due to their lack of work experience. However, this problem seems to be rather intense in Greece (OECD, 2005) and highlights the need for some measures that would facilitate employment of young females. To illustrate, in the UK, the same age group of females (15-24) have an odds ratio only 1.4 times greater than the 25-34 age group. The age groups 45-54 and 55+ are found to have lower odds of unemployment than the reference category in both Greece and the UK.

Finally, a negative time trend has been found to exist in both countries. In Greece this trend is stronger, as each additional year that goes by, the odds of being unemployed decreases significantly (.59), while in the UK, the associated odds ratio is fairly close to unity (0.91).

Regarding self-employment, several studies in the UK have examined the causes of the rise of it (e.g. Blanchflower and Oswald, 1990, Parker, 1996a), but most of the studies (e.g. Robson, 1998a, Robson, 1998b) focused on the labour market for males. Comparing both countries, we find that, in general, the opposite situation applies regarding self-employment. For instance, in Greece married females have a higher probability of being self-employed than single or divorced ones. Similarly, females who are head of the household have a higher chance of being an employee than being self-employed. Again the picture is the opposite in the UK as head of household females have a greater probability of being an entrepreneur than the spouse/partner group (.68). 
In terms of regional differences, the situation is once again the reverse. In particular, females that reside in London have a higher probability of being self-employed than residents outside of London ${ }^{3}$, while this probability is lower for capital city of Greece. Once again this has to do with the structures of the local economics as rural regions of Greece are based on the development of small family business. Over the short periods covered in the study, the trend in self-employment is found to be negative both in Greece and the UK (.72 and .94 respectively), with the trend in Greece being the stronger of the two. Finally, in the UK, females with low levels of qualifications account for the $28 \%$ of the self-employed. This share is considerably lower than the share for Greece (58\%). However, the odds ratios for the UK show that the selfemployed phenomenon is also more likely for females with low levels of education.

\section{Employment discrimination of female workers}

For the analysis of gender employment discrimination, we use the probability of being unemployed as the dependent variable. Two reasons justify the choice of this variable. First, the decision to participate in the labour market is likely to be driven by personal preferences, which means that differences between males and females cannot be interpreted as discriminatory. Second, it is assumed that unemployment cannot be preferred to employment by workers. This postulation is based on the reported definition of unemployment in the LFS, which is defined by the International Labour Organisation, which states that individuals are classified as unemployed when they are available for employment and are taking specific steps to seek paid employment. The latter feature of the definition implies that individuals must be seeking employment in order to be classified as unemployed. Thus, according to this

\footnotetext{
${ }^{3}$ For a discussion of regional variations in self-employment in the UK, see Robson (1998) and Storey and Johnson (1987).
} 
definition, the unemployment situation cannot be voluntary and, consequently, the unexplained differences on the unemployment rates of males and females might be interpreted as the extent of discrimination. Using the same approach, the employment discrimination has been studied for race (Shulman, 1987) and immigration (Price, 2001). Other studies have also addressed gender employment discrimination for several specific occupational groups, such as scientists and engineers (Finn, 1983), managers (Jones and Walsh, 1991) and US federal administrators (Long, 1976).

Tables 4 and 5 report the estimates of the nonlinear decomposition technique for the male/female employment gap. The two sets of coefficients used are based on separate logit regressions for males and females.

\section{[Table 4 here]}

\section{[Table 5 here]}

The employment gap between males and females is 1.53 points in the estimated likelihood of unemployment in Greece (see Table 4). The endowments of individuals account for only $0.27(18 \%)$ of the male/female difference in employment and the remaining unexplained part forms $82 \%$. This suggests that discrimination in the Greek labour market may account for a very important part of male-female unemployment gap and may be the factor most responsible for the dissimilarity in the employment position of males and females. Table 5 reports similar results for the UK, with the employment difference between males and females being 0.57. Thus, the total employment gap between males and females is much higher, indeed almost three times higher, in Greece (1.53) than it is in the UK (0.57). This result is in line with 
previous evidence (Olivetti and Petrongolo, 2006) that also observed a large gender employment gap in Greece, while the UK gap was one of the narrowest in Europe.

It is important to recall that employment discrimination involves the estimation of coefficients for males as well as females ${ }^{4}$. In Greece, the characteristics that seem to help a male worker to be better off in the labour market (regarding employment) are: being married, being in the age range between 35-44, and holding higher education. In the case of the UK, married men are less likely to be unemployed than any other marital status. Moreover, the age of the individual increases the likelihood of unemployment greatly and it can be assumed that ageing is a factor that contributes to the likelihood of unemployment. However, despite the country specific differences, the inter-country comparison of both markets yields more similarities in the case of males than for females.

There are several ways to interpret the extent of employment discrimination. In particular, the point where the existing methodological approaches often diverge is how to allocate the interaction term. The simplest interpretation is proposed by Oaxaca (1973) which considers the interaction either being totally a part of the unexplained or totally a part of the explained. In our estimation, the interaction is not significant for the case of Greece, while it is negative for the UK. In particular, the endowments (explained part) account just for the $18 \%$ and $14 \%$ of the total employment gap in Greece and the UK, respectively. This means that, despite the much larger employment gap, discrimination is almost the same in both countries (slightly higher in the UK). These results show that both labour markets are giving

\footnotetext{
${ }^{4}$ The estimates of the likelihood of unemployment for males are available from authors.
} 
little value to observed endowments, as most of the employment gap remains unexplained. Addressing this issue, Fortin (2005) stresses the relevance of some other variables related to the role of gender as a determinant of employment situation. For instance, women's attitudes and preferences, which may affect the intensity of job search, are found to play an important role in explaining the gender differences in wages and employment. Thus if female "choices" are not regarded as discrimination, then the unexplained part of the gap might be largely reduced. Nevertheless, our results are based on several observable human capital variables, which are the usual set of considered factors when analysing discrimination. The inclusion of more variables such as attitudes or roles that are linked to the social definition of the discrimination is likely to evolve alongside the rest of characteristics of females' labour markets.

\section{Conclusions}

This paper compared females' employment status in Greece and the UK, with the particular interest in measuring the level of employment discrimination. The purpose was to analyse the labour markets of two countries with different economic and institutional structures. We used the case of Greece as representative of Southern European economies where female unemployment is high, and the case of the UK as an example of Anglo-Saxon economies, where female unemployment is low. The results were obtained by using LFS micro-data and estimating an extension of the Oaxaca-Blinder methodology.

The results suggest that personal attributes of females, such as marital status, relationship to the $\mathrm{HH}$, education, region of residence, age and a number of other 
factors affect the employment status both in Greece and the UK. Interestingly, the patterns observed in Greece are in many ways dissimilar to those observed in the UK. The contrasts in the labour market outcomes caused by the same characteristics operating in quite different ways in the two countries are likely to be the result of a combination of differences in the economic structure and institutional characteristics.

The findings also suggest a large residual gap between male and female unemployment outcomes that cannot be explained by differences in their endowments or characteristics; this evidence is found for both countries. One explanation for the more favourable position of males is discrimination in the labour market. Again, there are differences between the two countries with respect to this result, as the absolute unemployment gap between males and females is three times as high in Greece than in the UK. However, the proportion of the gap that remains unexplained by the endowments of males and females, which may be associated with discrimination, is slightly higher in the UK than in Greece. This could be explained by the possible influence of some other labour market signals in the UK. Since this market is more flexible, the professional career of workers is usually developed in more than one company. The labour market may then create some mechanisms to signal the skills and capabilities of workers, such as on-the-job performance and career development. Due to labour market flexibility and job turnover the human capital attainments may be signalled more accurately, and the impact of other external signals such as education or demographic characteristics could be downgraded. If this is the case, the specified model, built upon the usual human capital variables, may overestimate the extent of discrimination in the UK, as it might not address the effect of all the 
available signals. Testing the effect of alternative signals could be an interesting extension to the presented evidence.

The findings of this paper might be interpreted under the light of the overall economic conditions of the examined period. During the 2000-2004 Greece experienced intense economic growth, mostly due to the preparations for the Athens Olympics in 2004. This provoked a steady raise on the labour force participation and employment (OECD, 2005), which, as our evidence confirms, strongly favoured the incorporation of female workers. In the UK, the same period is characterized by a sustained, but more moderate, economic growth where levels of female participation hold to their positive gap over the EU average. Under such economic conditions, evidence for Greece should be interpreted as the result of an economic boom, which means that they might overturn when such boom is over. On the contrary, results for the UK are taken from a period of relative economic stability which, in some extent, guarantees their permanence over time.

From a policy-making perspective, our findings show that in Greece, the effectiveness of the new measures inspired by the new constitution are yet to be confirmed. In particular, they are not very successful in their attempts to facilitate female participation in the labour market and to reduce prime age female unemployment. However, we found evidence of both increasing participation and declining unemployment. Additionally, we found a very high level of gender employment discrimination in both countries, which, by no means can be seen as compatible with the current anti-discrimination legislation. Nevertheless, it is possible that many of the 
beneficial effects of the 2001 constitutional change in Greece may be observed on the future, as outcomes of structural changes usually materialize in the long term.

There are several measures that may improve the described situation in Greece, where low participation and high unemployment are a big concern, and especially in rural areas. In particular, female participation could be facilitated by increasing public childcare facilities or subsidizing the fees for the use of private childcare. Additionally, measures encouraging flexible working patterns may also permit a better fit between work and family responsibilities. This would also enhance the employability of young females who are found to be worse off in the Greek labour market. Other measures that would promote youth employment include more internship programmes (STAGE) that would enable young females to gain experience as well as the ease of the high non-wage costs of new entrants in the labour market, so firms would have an incentive to hire young females. Regarding female residents of rural areas, the introduction of measures aiming to facilitate geographical mobility, such as incentives to emigrate or the improvement of commuting infrastructure that would also improve their labour market situation. The problem of female employment discrimination in both countries may also be tackled by improved monitoring of the selection processes of firms. Current labour inspection is mainly focused on preserving the rights of employees and, therefore, it might be overlooking to address discrimination against non-participant and unemployed females. This can also be facilitated by subsidizing the cost that firms bear during females' absence due to maternity leave. 


\section{References}

Anker, R. (1997), "Theories of occupational segregation by sex: an overview", International Labor Review, Vol. 136 No. 3, pp. 315-339.

Azmat, G. Guell, M. and Manning, A. (2006), "Gender gaps in unemployment rates in OECD countries", Journal of Labor Economics, Vol. 24 (1), pp 1-37.

Blanchflower, D. G. and Oswald, A.J (1990), "Self-employment and the Enterprise Culture" in R. Jowell, S. Witherspoon and L. Brook (eds.), British Social Attitudes: the 1990 Report, Aldershot: Gower.

Blau, F. and Kahn, L. (2003), "Understanding international differences in the gender pay gap", Journal of Labor Economics, 21 (1), pp. 106-144.

Blinder, A. (1973), "Wage discrimination: Reduced form and structural variables", Journal of Human Resources, Vol. 8, pp. 436-455.

Cholezas, I. (2005), Private returns to education in Greece and the European Union, Doctoral Thesis, Department of International and European Economic Studies, Athens University of Economics and Business.

Cholezas, I. and Tsakloglu, P. (2005), "Gender earnings differentials in the Greek labour market", Athens University of Economics and Business, IMOP and IZA

Del Boca, D. Pasqua, S and Prozanto, C. (2005), "Fertility and employment in Italy, France and the UK", Labour Vol. 19, pp. 51-77.

European Commission (2006), Employment in Europe 2005, Employment and Social Affairs, Brussels.

European Communities (2003), The European Union Labour Force Survey: methods and definition 2001, Luxemburg.

Fairlie, R. (2003), “An extension of the Blinder-Oaxaca decomposition technique to logit and probit models", Center Discussion Paper no. 873, Yale University. 
Finn, M.G. (1983), "Understanding the higher unemployment rate of women scientist and engineers", American Economic Review, Vol. 73 No. 5, pp.1137-1141.

Fortin, N. (2005), "Gender role attitudes and the labour market outcomes of women across OECD countries", Oxford Review of Economic Policy, 21 (3), 416-438.

Gomulka, J. and Stern, N. (1990), "The employment of married women in the United Kingdom 1970-83" Economica 57, 171-199.

Gutierrez-Domenech, M. (2004), "Female labour force participation in the UK: evolving characteristics or changing behaviour?", Bank of England, ISSN 1368-5562 Hart, R.A. (2007), “Women doing men's work and women doing women's: female work and pay in British wartime engineering", Explorations in Economic History, Vol. 44 No. 1, pp.114-130.

Jaumotte, F. (2003) "Labor force participation of women: evidence of the role of policy and other determinants in OECD countries", Economic Studies 37 (2), pp. 51108.

Jones, J.C.H and Walsh, W.D. (1991), "Product market imperfections, job content differences and gender employment discrimination at the management level: some evidence from the Canadian manufacturing sector in 1971 and 1981”, Canadian Journal of Economics, Vol. 24 No. 4, pp. 844-859.

Kanellopoulos, C.N. (1980), Individual pay discrimination and labour mobility in Greece in the early 1960s, PhD Thesis, University of Kent.

Kanellopoulos, C.N. and K.G. Mavromaras (2002), "Male-female labour market participation and wage differentials in Greece”, Labour, Vol. 16, pp.771-801.

Leibenstein, H. (1967), "Rates of return to education in Greece", Economic Development Report No 94, Harvard University. 
Livanos, I. (2007), “The incidence of long-term unemployment: evidence from Greece”, Applied Economics Letters, Vol. 14, pp. 405-408.

Livanos, I. (2008), "What determines self-employment? A comparative study", Applied Economics Letters, 1-6, ifirst.

Long, J.E. (1976), "Employment discrimination in the federal sector", Journal of Human Resources, Vol. 11 No, 1, pp.86-97.

Nicolitsas, D. (2006), "Female labour force participation in Greece: developments and determining factors", Economic Bulletin, 26, pp.7-35.

Nielsen, H. (1998), "Discrimination and detailed decomposition in a logit model", Economics Letters, Vol. 61, pp. 115-120.

Oaxaca, R. (1973), "Male-female wage differentials in urban labour markets", International Economic Reviews, Vol.14, pp. 693-709.

OECD (2003), "Labour Force Participation of Women: Empirical Evidence on the Role of Policy and other Determinants in OECD Counties", OECD Economic Studies, No. 37 .

OECD (2005), Economic Survey of Greece 2005, OECD.

OECD (2007), Economic Survey of Greece 2007, OECD.

Olivetti, C. and Petrongolo, B. (2006), "Unequal Pay or Unequal Employment? A Cross-Country Analysis of Gender Wage Gaps", IZA Discussion papers, IZA DP No 1941, Bonn.

Parker, S. C. (1996), “A Time Series Model of Self-employment Under Uncertainty” Economica, Vol. 63 No. 431, pp. 459-475.

Price, S.W. (2001), "The unemployment experience of male immigrants in England", Applied Economics, Vol. 33 No. 2, pp. 201-215. 
Psacharopoulos, G. (1983), "Sex discrimination in the Greek labour market", Journal of modern Greek studies Vol. 1, pp.339-358.

Robson, M. T. (1998a), “The rise of self-employment amongst UK males", Small Business Economics, Vol. 10, pp. 199-212.

Robson, M. T. (1998b), "Self-employment in UK regions", Applied Economics, Vol. 30, pp. 313-322.

Schulman, S, (1987), "Discrimination, human capital and black-white unemployment", Journal of Human Resources, Vol. 22 No. 3, pp. 361-376.

Storey, D. and Johnson, S. (1987), "Regional variations in entrepreneurship in the UK”, Scottish Journal of Political Economy, Vol. 34, pp. 161-173. 
Table 1. Descriptive statistics of the sample (\%). The female labour market in Greece and the UK.

\begin{tabular}{|c|c|c|c|c|c|c|c|c|}
\hline & \multicolumn{2}{|c|}{ Total } & \multicolumn{2}{|c|}{ Participants } & \multicolumn{2}{|c|}{ Unemployed } & \multicolumn{2}{|c|}{ Self-employed } \\
\hline & UK & Greece & UK & Greece & UK & Greece & UK & Greece \\
\hline \multicolumn{9}{|l|}{ Marital Status } \\
\hline Single & 40.8 & 21.5 & 30.8 & 26.3 & 50.1 & 51.0 & 16.5 & 11.4 \\
\hline Married & 43.4 & 60.3 & 57.3 & 66.8 & 34.4 & 40.9 & 67.8 & 81.4 \\
\hline Widow & 9.0 & 15.5 & 2.1 & 3.0 & 1.5 & 2.4 & 6 & 4.8 \\
\hline Divorced & 6.6 & 2.6 & 9.1 & 3.9 & 10.6 & 9.7 & 9.5 & 2 \\
\hline \multicolumn{9}{|l|}{ Age Group } \\
\hline $15-24$ & 17.5 & 8.2 & 14.2 & 4.3 & 32.2 & 12.3 & 2.7 & 3.6 \\
\hline $25-34$ & 20.2 & 26.4 & 22.4 & 32.4 & 22.5 & 46.2 & 17.1 & 16.8 \\
\hline $35-44$ & 23.4 & 30.2 & 27.5 & 35.9 & 24.8 & 27.4 & 32.5 & 25.3 \\
\hline $45-54$ & 19.5 & 22.7 & 23.0 & 23.8 & 14.5 & 12.7 & 28 & 26.8 \\
\hline $55+$ & 18.8 & 12.3 & 12.2 & 3.4 & 5.2 & 1.1 & 19.5 & 27.3 \\
\hline \multicolumn{9}{|c|}{ Qualification [Greece] } \\
\hline Postgraduate & & 0.1 & & 0.5 & & 0.2 & & 0.3 \\
\hline Graduate & & 7.9 & & 18 & & 9.7 & & 8.9 \\
\hline Other Qualification & & 4.2 & & 9 & & 3.8 & & 4.5 \\
\hline Secondary & & 33 & & 41.5 & & 28 & & 28 \\
\hline Primary or below & & 55 & & 30 & & 58 & & 58 \\
\hline \multicolumn{9}{|l|}{ Qualification [UK] } \\
\hline NVQ 5 & 7.4 & & 8.0 & & 7.7 & & 8.3 & \\
\hline NVQ 4 & 24.2 & & 28.3 & & 14.1 & & 34 & \\
\hline NVQ 3 & 11.3 & & 11.6 & & 9.2 & & 14 & \\
\hline NVQ 2 & 18.9 & & 19.3 & & 22.0 & & 15 & \\
\hline NVQ 1 & 19.8 & & 19.8 & & 26.6 & & 16 & \\
\hline No qualification & 18.3 & & 12.7 & & 20.1 & & 12 & \\
\hline \multicolumn{9}{|l|}{ Relation to $\mathrm{HH}$} \\
\hline $\mathrm{HH}$ & 22 & 17.4 & 20.2 & 15.2 & 13 & 10 & 19.5 & 9.8 \\
\hline Spouse/Partner & 47 & 50 & 65.2 & 55.7 & 49 & 42 & 76 & 77 \\
\hline Child & 27.5 & 27.5 & 11.9 & 26.7 & 34 & 44 & 2.8 & 11.5 \\
\hline Parent & 0.4 & 2.9 & 0.1 & 0.5 & 2 & 2 & 0.05 & 0.8 \\
\hline Other relative & 3.2 & 2 & 2.5 & 1.5 & 2 & 1.5 & 1.4 & 0.6 \\
\hline
\end{tabular}


Table 2: Logit regression results. $2^{\text {nd }}$ Quarter 2000-2004 Greek LFS data. Odds ratio ${ }^{\#}$

\begin{tabular}{|c|c|c|c|c|}
\hline Variables & & Participation & Unemployment & $\begin{array}{c}\text { Self } \\
\text {-Employment }^{1} \\
\end{array}$ \\
\hline \multirow[t]{4}{*}{ Marital Status } & Single & $.31 * * *$ & $3.57 * * *$ & $1.10 * * *$ \\
\hline & Married & $\S$ & $\S$ & $\S$ \\
\hline & Widow & $.11 * * *$ & $15.60 * * *$ & $1.91 * * *$ \\
\hline & Divorced & $.69 * * *$ & $4.04 * * *$ & $.81 * * *$ \\
\hline \multirow[t]{5}{*}{ Age Group } & $15-24$ & $.23 * * *$ & $5.35 * * *$ & $1.60 * * *$ \\
\hline & $25-34$ & $\S$ & $\S$ & $\S$ \\
\hline & $35-44$ & $1.13 * * *$ & $.70 * * *$ & $1.13 * * *$ \\
\hline & $45-54$ & $.46^{* * *}$ & $1.27 * * *$ & $1.48 * * *$ \\
\hline & $55+$ & $.01 * * *$ & $35.34 * * *$ & $6.34 * * *$ \\
\hline \multirow[t]{15}{*}{ Region } & Eastern Macedonia & .95 & $1.47 * * *$ & $1.33 * * *$ \\
\hline & Central Macedonia & $1.07 * * *$ & $1.18 * * *$ & $1.75 * * *$ \\
\hline & Western Macedonia & $1.31 * * *$ & $1.16^{* * *}$ & $1.30 * * *$ \\
\hline & Ipeiros & .96 & $1.52 * * *$ & $1.65 * * *$ \\
\hline & Thessaly & 1.02 & $1.35 * * *$ & 1.73 \\
\hline & Ionian Islands & $.71 * * *$ & $2.09 * * *$ & $1.93 * * *$ \\
\hline & Western Greece & $.82 * * *$ & $1.71 * * *$ & $1.75 * * *$ \\
\hline & Sterea Ellada & $1.24 * * *$ & .93 & $1.32 * * *$ \\
\hline & Rest of Attica & $1.14 * * *$ & $.81 * * *$ & $1.08 * * *$ \\
\hline & Peloponnisos & $.91 * * *$ & $1.35^{* * * *}$ & $1.87 * * *$ \\
\hline & North Aegean & $.57 * * *$ & $1.99 * * *$ & $2.15^{* * *}$ \\
\hline & South Aegean & 1.05 & $1.39 * * *$ & $1.56^{* * *}$ \\
\hline & Crete & $.73 * * *$ & $1.43 * * *$ & $1.50 * * *$ \\
\hline & Athens & $\S$ & $\S$ & $\S$ \\
\hline & Thessalonica & $.94 * *$ & $1.10 * * *$ & $1.18 * * *$ \\
\hline \multirow{5}{*}{$\begin{array}{l}\text { Level of } \\
\text { Qualification }\end{array}$} & Post graduates & $4.1 * * *$ & $.30 * * *$ & $.70 * * *$ \\
\hline & Graduates & $\S$ & $\S$ & $\S$ \\
\hline & Other & $3.65 * * *$ & $.54 * * *$ & $.78 * * *$ \\
\hline & Secondary & $.31 * * *$ & $2.25^{* * *}$ & $.70 * * *$ \\
\hline & Primary or below & $.81 * * *$ & $1.1 * * *$ & $1.4 * * *$ \\
\hline \multirow[t]{5}{*}{ Relation to $\mathrm{HH}$} & $\mathrm{HH}$ & $11.10^{* * *}$ & $\S$ & $\S$ \\
\hline & Spouse/partner & $\S$ & $23.11 * * *$ & $1.86^{* * *}$ \\
\hline & Child & $8.63 * * *$ & $2.20 * * *$ & $1.52 * * *$ \\
\hline & Parent & $2.93 * * *$ & $5.97 * * *$ & $2.02 * * *$ \\
\hline & Other Relative & $9.50 * * *$ & $1.59 * * *$ & $.91 * * *$ \\
\hline Time & $\mathrm{t}$ & $1.34 * * *$ & $.59 * * *$ & $.72 * * *$ \\
\hline Log Likelihood & & -60896 & -36879 & -52589 \\
\hline Pseudo R2 & & .3311 & .3555 & 0.7119 \\
\hline Observations & & 207,772 & 207,772 & 273,717 \\
\hline \multicolumn{5}{|c|}{$\begin{array}{l}\text { \# Percentage changes in the odds of being in each status, } \S \text { Indicates the omitted dummy variable } \\
* * *=\text { statistically significant at the } 1 \% \text { level, } * *=\text { statistically significant at the } 5 \% \text { level } \\
{ }^{1} \text { Occupation and sector variables are included in the self employed logit regression. }\end{array}$} \\
\hline
\end{tabular}


Table 3: Logit regression results, $2^{\text {nd }}$ Quarter 2001-2004 UK LFS data.Odds ratio ${ }^{\#}$

\begin{tabular}{|c|c|c|c|c|}
\hline Variables & & Participation & Unemployment & $\begin{array}{c}\text { Self- } \\
\text { employment }^{1}\end{array}$ \\
\hline \multirow[t]{4}{*}{ Marital Status } & Single & $1.56^{* * *}$ & $.62 * * *$ & $.61 * * *$ \\
\hline & Married & $\S$ & $\S$ & $\S$ \\
\hline & Widow & $.49 * * *$ & $1.44 * * *$ & $1.57 * * *$ \\
\hline & Divorced & $1.51 * * *$ & $.64 * * *$ & $.68 * * *$ \\
\hline \multirow[t]{5}{*}{ Age Group } & $15-24$ & $1.53 * * *$ & $1.42 * * *$ & $.76^{* * * *}$ \\
\hline & $25-34$ & $\S$ & $\S$ & $\S$ \\
\hline & $35-44$ & $1.63 * * *$ & $.64 * * *$ & $.78 * * *$ \\
\hline & $45-54$ & $1.82 * * *$ & $.44 * * *$ & $.69 * * *$ \\
\hline & $55+$ & 1.04 & $.70 * * *$ & 1.06 \\
\hline \multirow[t]{12}{*}{ Region } & North & .91 & .96 & $.77 * * *$ \\
\hline & Yorkshire and Humberside & .99 & $.78 * * *$ & $.73 * * *$ \\
\hline & East Midlands & $1.22 * * *$ & $.58 * * *$ & $.69 * * *$ \\
\hline & East Anglia & $1.16^{* *}$ & $.62 * * *$ & $.74 * * *$ \\
\hline & London & & & \\
\hline & Rest of South East & $1.20 * * *$ & $.59 * * *$ & $.73 * * *$ \\
\hline & South West & $.97 * * *$ & $.77 * * *$ & $.94 * *$ \\
\hline & West Midlands & 1.20 & $.63 * * *$ & $.66^{* * *}$ \\
\hline & North West & $1.01 * * *$ & $.71 * * *$ & $.69 * * *$ \\
\hline & Wales & .80 & 1.11 & .97 \\
\hline & Scotland & $1.16 * * *$ & $.76^{* * *}$ & $.68 * * *$ \\
\hline & Northern Ireland & $.66 * * *$ & $1.25 * *$ & $.83 * * *$ \\
\hline \multirow[t]{6}{*}{ Level of Qualification } & No qualification & $\S$ & $\S$ & $\S$ \\
\hline & NVQ 1 & $1.74 * * *$ & $.07 * * *$ & $.16 * * *$ \\
\hline & NVQ 2 & $1.85 * * *$ & $.05 * * *$ & $.13 * * *$ \\
\hline & NVQ 3 & $1.55 * * *$ & $.05 * * *$ & $.19 * * *$ \\
\hline & NVQ 4 & $1.47 * * *$ & $.08 * * *$ & $.20 * * *$ \\
\hline & NVQ 5 & $6.49 * * *$ & $.25 * * *$ & $.36 * * *$ \\
\hline \multirow[t]{5}{*}{ Relation to $\mathrm{HH}$} & $\mathrm{HH}$ & $.89 * * *$ & $\S$ & $\S$ \\
\hline & Spouse/partner & $\S$ & $.52 * * *$ & $.68 * * *$ \\
\hline & Child & $.47 * * *$ & $1.63 * * *$ & $1.73 * * *$ \\
\hline & Parent & $.30 * * *$ & $2.21 * * *$ & 1.27 \\
\hline & Other Relative & $.44 * * *$ & $1.39 * * *$ & $1.20 * * *$ \\
\hline Time & $\mathrm{t}$ & $1.09 * * *$ & $.91 * * *$ & $.94 * * *$ \\
\hline \multicolumn{2}{|l|}{ Log Likelihood } & -30263 & -18787 & -52589 \\
\hline \multicolumn{2}{|l|}{ Pseudo R2 } & .8385 & .8989 & .7119 \\
\hline \multicolumn{2}{|l|}{ Observations } & 273,717 & 273,717 & 273,717 \\
\hline \multicolumn{5}{|c|}{$\begin{array}{l}\#=\text { percentage changes in the odds of being in each status, } \S=\text { indicates the omitted dummy variable } \\
* * *=\text { statistically significant at the } 1 \% \text { level, } * *=\text { statistically significant at the } 5 \% \text { level } \\
{ }^{1} \text { Occupation and sector variables are included in the self employed logit regression. }\end{array}$} \\
\hline
\end{tabular}


Table 4 Decomposition of the male/female difference in the probability of unemployment, Greece

\begin{tabular}{lrrr}
\hline & Coefficients & $\%$ & Standard Error \\
\cline { 2 - 4 } Male/ Female gap & $1.53 * * *$ & & 0.01 \\
Endowments & $0.27 * * *$ & 18 & 0.04 \\
Coefficients & $1.19 * * *$ & 78 & 0.02 \\
Interaction & 0.06 & 4 & 0.05 \\
\hline
\end{tabular}

High estimates: females, low estimates: males, $* * *=$ statistically significant at the $1 \%$ level

Table 5 Decomposition of the male/female difference in the probability of unemployment, UK

\begin{tabular}{lrrr}
\hline & Coefficients & $\%$ & Standard Error \\
\cline { 2 - 4 } Male/ Female gap & $0.57 * * *$ & 0.01 \\
Endowments & $0.08^{* * *}$ & 14 & 0.02 \\
Coefficients & $0.86^{* * *}$ & 150 & 0.01 \\
Interaction & $-0.36^{* * *}$ & -63 & 0.02 \\
\hline High estimates: females, low estimates: males, $* * *=$ statistically significant at the $1 \%$ level \\
\hline
\end{tabular}




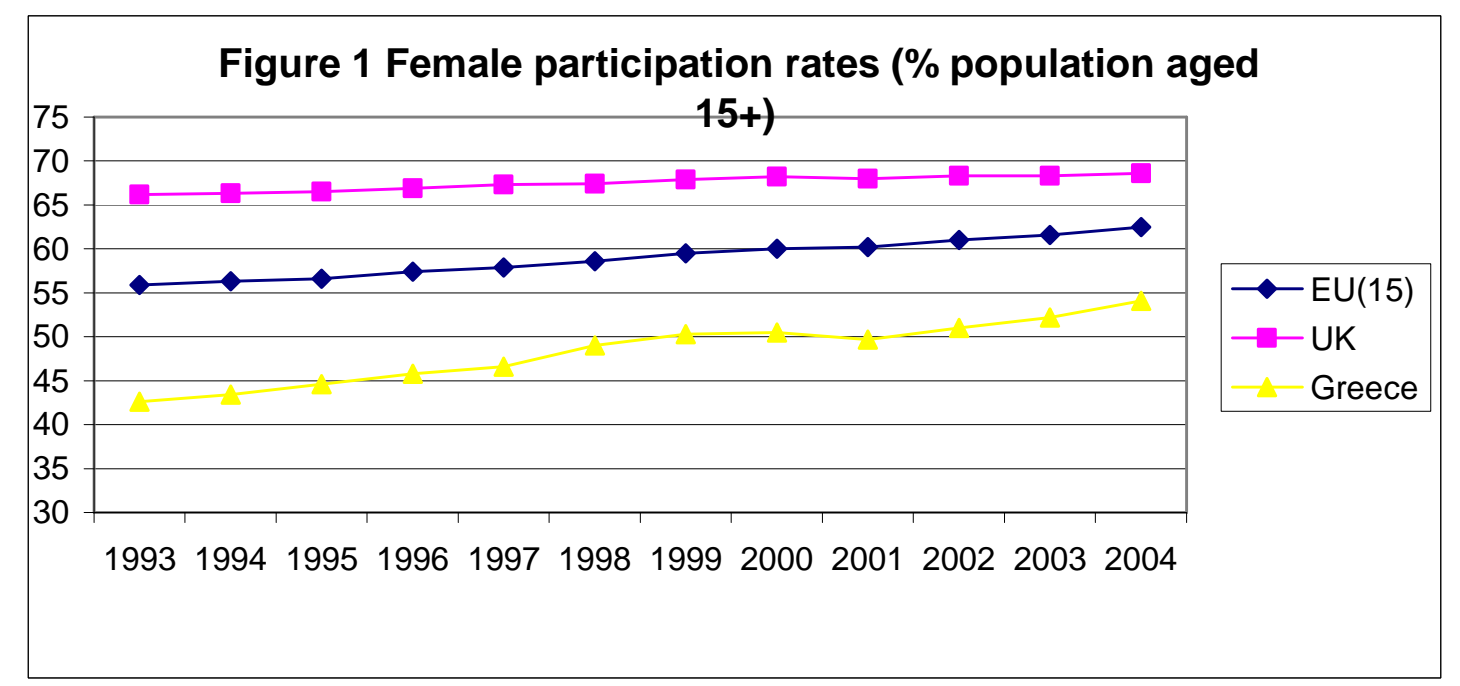

Source: Employment in Europe 2005, European Commission (2006).

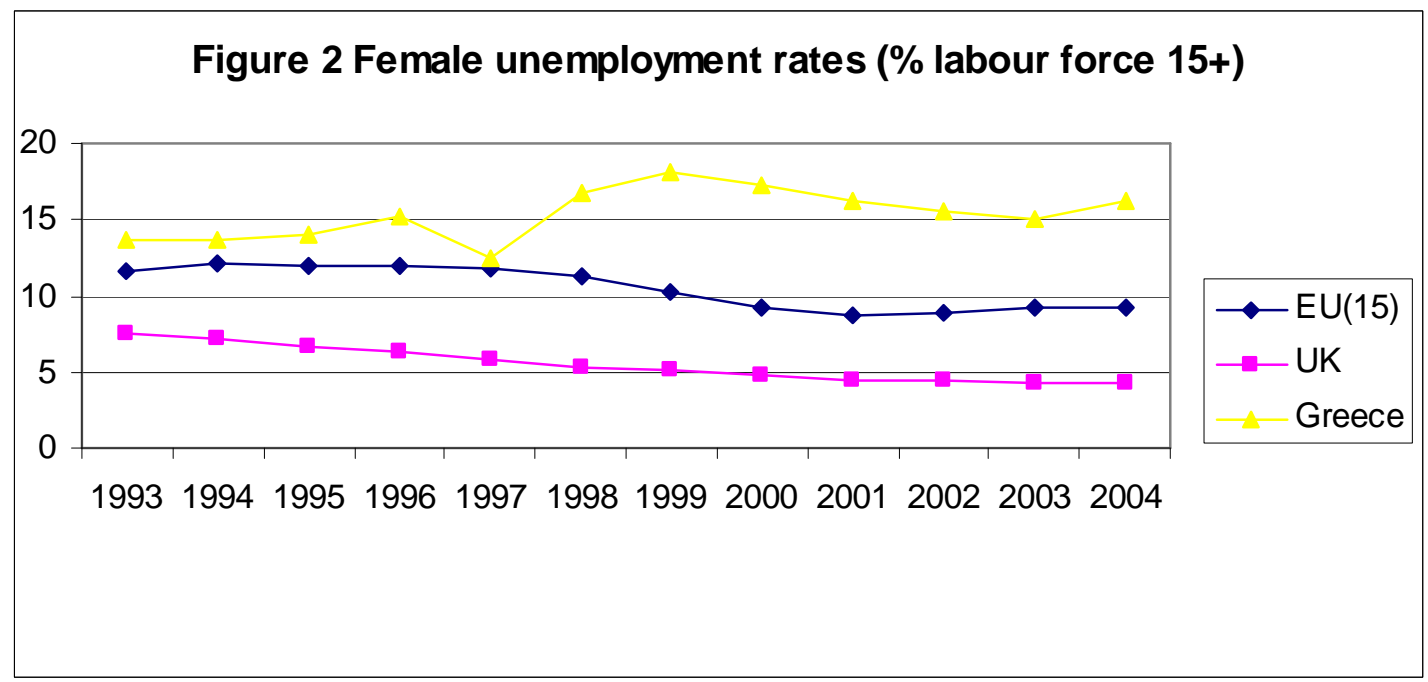

Source: Employment in Europe 2005, European Commission (2006)

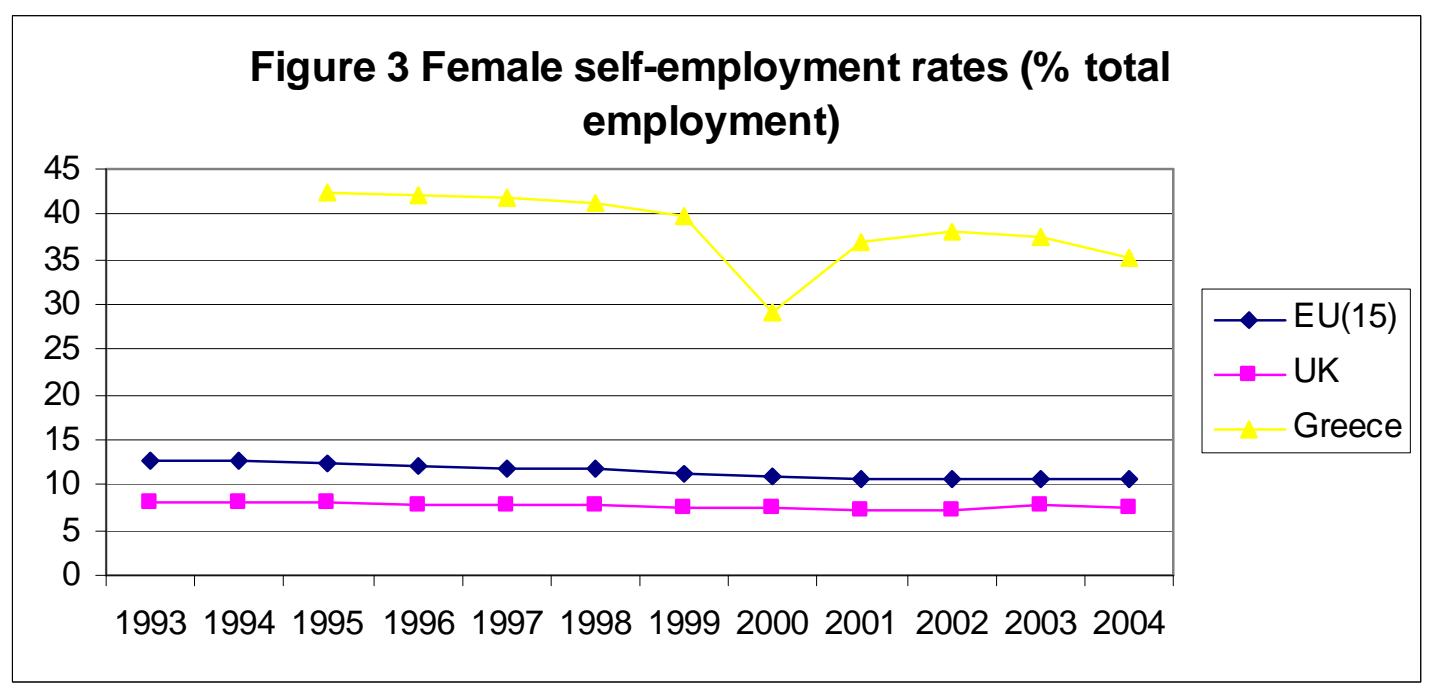

Source: Employment in Europe 2005, European Commission (2006) 